\title{
HÁ TRADUÇÃO PARA O TEXTO LITERÁRIO?
}

\author{
Bernardo Romagnoli Bethônico (FALE - UFMG)
}

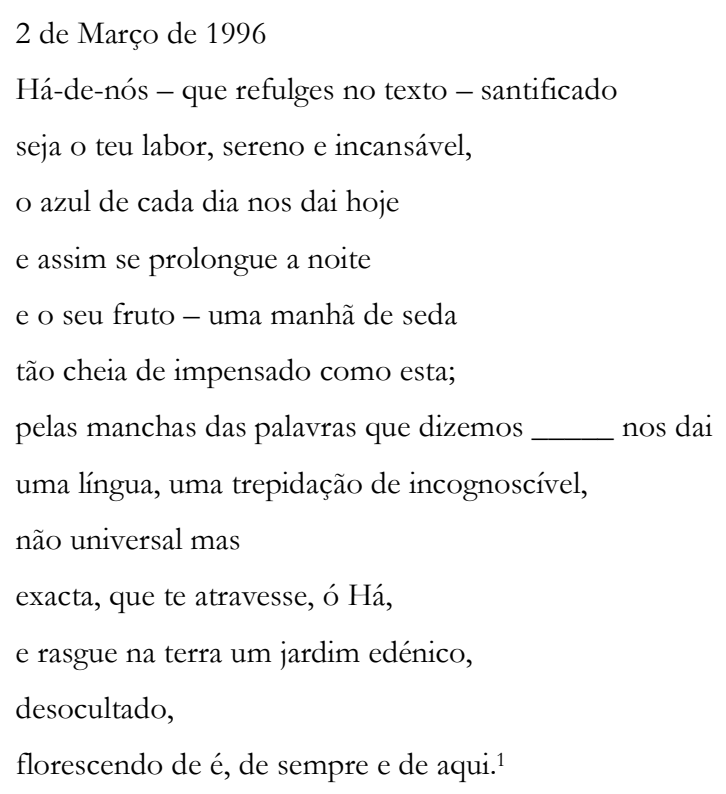

O que nos passa o "Há" de que Llansol fala ? Para onde nos leva?

"Pois que 'diz' uma obra literária ? Que comunica ela ? Muito pouco para quem a compreende." ${ }^{2}$

Comentando Benjamin em Torres de Babel, Derrida se referirá à tese de que para um texto poético ou sagrado (e conseqüentemente para suas traduções), a comunicação não é o essencial - o objetivo de qualquer obra de arte não é e nunca foi comunicar-se. "Esse questionamento não concerne diretamente à estrutura comunicante da linguagem, mas, de preferência, à hipótese de um conteńdo comunicável que se distinguiria rigorosamente do ato lingüistico da comunicação." [grifo meu]

Derrida, então, pergunta: “...uma abertura é assim feita em direção à dimensão performativa dos enunciados ?"4 . A dimensão em que "dizer é fazer", em que as coisas existem porque são ditas, a dimensão na qual a pronúncia está colada

\footnotetext{
${ }^{1}$ Llansol, 1997, p. 11.

${ }^{2}$ Benjamin, 1992 , p. 5

${ }^{3}$ Derrida, 2002, p. 34

${ }^{4}$ idem
} 
à realidade, em que os verbos são de fato o que eles dizem: não seria isto o texto, uma abertura para a atualidade viva, um "Há" ? Llansol responde a Derrida que a abertura de um conteúdo que se distinguiria rigorosamente do ato lingüístico, da comunicação, deve se dar através de uma língua "não universal mas/ exacta, que te atravesse" e "rasgue na terra um jardim edénico, / desocultado,/ florescendo de é, de sempre e de aqui."

Uma língua exata; uma língua de é. A língua que é antes da confusão que separa o homem por meio das línguas, antes de Babel, edênica. A língua que todo tradutor quer traduzir. A língua que, apesar ou por causa da confusão (da tradução), sobrevive.

...alguma linguagem originária, palavra suprema que teria sido suficiente falar para o dizer verdadeiro. Benjamin retém alguma coisa desse sonho. Todas as línguas, observa ele, visam à mesma realidade, mas não da mesma forma. (...) Tomadas uma a uma, as línguas são incompletas. Pela tradução, eu não me contento em substituir um modo por outro, um caminho por outro caminho, mas eu aceno a uma língua superior que seria a unidade complementar de todos esses modos de visada diferentes e que falaria idealmente à junção do mistério reconciliado de todas as línguas faladas por todas as obras. ${ }^{5}$

Antonin Artaud parecia estar atento a esse mistério. Ao tentar traduzir "Jabberwocky", de Lewis Carrol, ele escreve em carta a Henri Parisot:

Pode-se inventar uma linguagem própria, fazer com que a linguagem fale com um sentido extragramatical, mas é preciso que haja um sentimento válido em si, que provenha do horror - o horror, este velho servo da dor, sexo como uma coleira subterrânea de aço produzindo seus versos a partir da sua doença: o ser, e nunca tolerando que o esqueçam ${ }^{6}$. [o grifo é meu]

$\mathrm{O}$ ser. As palavras. As palavras fundadas no ser, nunca tolerando que o esqueçam. As palavras sendo usadas para lembrar ao ser de que ele existe, e portanto vivas. Nunca tolerando que as esqueçam. Artaud é um dos que entram em contato com a estranha vida delas:

\footnotetext{
${ }^{5}$ Blanchot, p. 2

${ }^{6}$ Artaud, 1983, p. 116
} 
Sou um ignorante. Acreditava estar seguro do sentido das palavras, acreditava-me até um certo ponto ser seu mestre. Mas agora que eu as experimentei um pouco, ele me escapa./ Por quê ? / As palavras valiam pelo que eu as fazia dizer, isto é, pelo que lhes colocava dentro. / Mas eu nunca pude saber exatamente até que ponto eu tinha razão.?

Artaud, sem saber mais para que (ou porque) as palavras valiam, via-as escaparem de seu sentido. Fugidio movimento de vida que Françoise, personagem de Luis Vilela, também perscrutará:

Beto diz que a gente pode aprender tudo com as palavras, mas para isso é preciso a gente gostar delas feito a gente gosta das pessoas. Eu também já pensei isso uma vez. Já reparou como é engraçado uma palavra se a gente fica olhando para ela muito tempo e pensando nela ? É engraçado, ela parece que começa a mexer, a viver; parece uma coisa viva. Palavras parecem uma porção de bichinhos brincando; brincando de serem palavras; já reparou nisso? Fale uma palavra que você acha bonita...8

É porque as palavras são assim, vivas, que a tradução se faz.. Tradução: a possibilidade na existência das palavras. Para que seu "Há" flua e respire, para que elas sobrevivam, são traduzidas. Benjamin caracterizará o tradutor como o "agente da sobrevida", que é aquele que exerce a tarefa de fazer a obra ultrapassar determinado limite, o limite da língua, para sobreviver em outro. Nessa tarefa o tradutor deve buscar aquilo que no texto sobrevive ao tempo e a qualquer outra coisa, a qualquer outro limite: “...a tradução mantém um vínculo estreito com o original. (...) Pode-se chamá-lo natural e, mais propriamente, vínculo de vida. (...) Por certo menos de sua vida que de sua sobrevivência." Derrida comenta: "Tal sobrevida dá um pouco mais de vida, mais que uma sobrevivência. A obra não vive apenas mais tempo, ela vive mais e melhor, acima dos meios de seu autor."10

Acima dos meios de si mesmo estava Hölderlin, esse autor alemão que chega até nós através de Maria Gabriela Llansol, com seu espírito dividido "em miríades

\footnotetext{
${ }^{7}$ Artaud apud Rey, 2002, p. 54

${ }^{8}$ Vilela, 1999, p. 84

${ }^{9}$ Benjamin, 1992, p. 7

${ }^{10}$ Derrida, 2002, p. 33
} 
de luzes dispersas." " Hölderlin traduzia. Benjamin diz que em suas traduções “...a harmonia das línguas é tão profunda que o sentido é apenas tangido pela linguagem como uma harpa eólia ao vento. (...) Nelas o sentido rola de abismo em abismo até quase perder-se nas insondáveis profundezas da linguagem."12 Se, ao experimentar a natureza própria das palavras, Artaud e Françoise vêem desaparecer justamente aquilo que elas trazem dentro de si, está claro que a experiência aí é uma experiência que ocorre na letra, no lado de fora. A palavra em si nomeia o inominável e ponto. As "profundezas da linguagem" são talvez a superfície na palavra, a sua pronúncia, a sua grafia, o seu uso. "A sensação não se realiza no material, sem que o material entre inteiramente na sensação, no percepto ou no afecto. Toda a matéria se torna expressiva."13

E Hölderlin, esse tradutor que tratará a matéria, em traduções de uma literalidade incomparável, é justamente o poeta que dirá que "No poema, a sensação fala idealmente" ${ }^{\text {"14 }}$ Dessa forma, a tradução do texto literário não começa na transmissão de um conteúdo, de uma informação, um sentido; nem tampouco por uma representação da obra a ser traduzida, substituindo-se palavras equivalentes; mas antes por um exercício de escuta, por um cuidado com a sensação que está ali a falar, sensação que é a abertura de um conteúdo diverso do representativo, do comunicativo - conteúdo atuante, performativo, apresentativo, que aponta para uma dicção que cria a sua própria realidade. $O$ tradutor não representa mais, ele atua. As traduções de Hölderlin, no oitocentos alemão, foram tachadas negativamente de "sem sentido". Nessa época, a arte era circundada por idéias mais platônicas. Hoje muito já se fala sobre o sentido que "cessou de ser a linha divisória para o fluxo da linguagem e para o fluxo da revelação" ${ }^{15}$ Se o texto, pois, não comunica nada, ele revela.

\footnotetext{
${ }^{11}$ Llansol, 1993, p. 11

${ }^{12}$ Benjamin apud Campos, 1977, p. 95

${ }^{13}$ Deleuze, 1992, p. 217

${ }^{14}$ Hölderlin, 1994, p. 59

${ }^{15}$ Derrida, 2002, p. 71
} 


\section{Referências Bibliográficas}

ARTAUD, Antonin. Os escritos de Antonin Artand - Tradução, prefácio, seleção e notas Cláudio Willer. Porto Alegre: L\&PM, 1983.

BENJAMIN, Walter. Die Aufgabe der Ubersetzers, A tarefa do tradutor. Trad. Dirce Riedel, Luiz Costa Lima e outros. Rio de Janeiro: UERJ, 1992.

BLANCHOT, Maurice. “Traduzir”. Trad. Cynthia Santos Barra. (Inédito)

CAMPOS, Haroldo de. A arte no horizonte do provável. São Paulo: Perspectiva, 1997. Pp. 93-107: A palavra vermelha de Hölderlin.

DELEUZE, Gilles; GUATARRI, Felix. O que é a filosofia? Rio de Janeiro: Ed. 34, 1992.

DERRIDA, Jacques. Torres de Babel. Belo Horizonte: Editora UFMG, 2002.

HÖLDERLIN, Friedrich; DASTUR, Françoise. Reflexões. Rio de Janeiro: Relume Dumará,1994.

LLANSOL, Maria Gabriela. Hölder, de Hölderlin. Lisboa: Colares Editora, 1993.

LLANSOL, Maria Gabriela. $O$ Sonho de que temos a linguagem. In: COLÖQUIO/LETRAS, Lisboa, Fundanbenkian, n. 143/144, Janeiro-Julho 1997.

REY, Jean-Michel. O nascimento da poesia: Antonin Artaud. Belo Horizonte: Autêntica, 2002.

VILELA, Luis. "Françoise”. In:Tarde da Noite: contos. São Paulo, Ática, 1999. 